\title{
O olhar estrangeiro de Lina Bo Bardi
}

Andre Reis Balsini'

DOI 10.20396/eha.vil4.3331

A condição de um olhar estrangeiro, tema de que trata o artigo, é um assunto subjetivo. Uma pessoa não nasce estrangeira, torna-se. Lina Bo Bardi (1914-1992) foi uma italiana naturalizada brasileira. O princípio da formação de seu olhar se deu na Itália, nos anos em que estudou arquitetura na Escola Superior de Roma e na vivência profissional em Milão. Um olhar marcado pelo testemunho da guerra e do fascismo. Em 1946, saindo de Nápoles, Lina deixa a Itália após seu casamento com o jornalista P. M. Bardi, partindo de navio rumo à América do Sul. Desde o alto mar, o encontro com o horizonte brasileiro é registrado em aquarelas. Nas suas palavras, a chegada ao Rio de Janeiro é a "primeira mensagem de paz após o dilúvio da Segunda Guerra Mundial. Me senti num país inimaginável, onde tudo era possível"².

Uma aventura do olhar

O 'estrangeiro' está sempre já delineado - latente e invisível - nas brechas da nossa identidade, na trilha aberta por nossa própria indeterminação. Não podemos apanhá-lo fora, só o tocamos dentro (de nós mesmos), pagando o preço da nossa própria transformação. ${ }^{3}$

O olhar da viajante busca um sentido para um novo mundo indeterminado. O deslocamento da Itália ao Brasil traduz uma mudança essencial para o olhar de Lina Bo Bardi. Nesse contexto, a chave de leitura utilizada no artigo vai se fundamentar pelo conceito de cronotopo, de Bakhtin, em que tempo mais espaço são o substrato para uma síntese estética. A cronotopia envolve uma "interligação fundamental das relações temporais e espaciais, artisticamente assimiladas". Aqui, a história se traduz em narrativa. A partir dessa perspectiva, se caracteriza o cronotopo de um "tempo de aventuras" em um mundo estrangeiro, onde tudo é indeterminado, desconhecido, e alheio. Um

\footnotetext{
1 Doutorando em Arquitetura e Urbanismo pela Universidade Presbiteriana Mackenzie, SP. Professor no curso de Arquitetura e Urbanismo da Universidade Nove de Julho, SP. http://lattes.cnpq.br/0115527277877070

2 BARDI, L.B. Curriculum literário. In: FERRAZ, M. C. (Org). Lina Bo Bardi. São Paulo, Instituto Bardi: Casa de Vidro: Romano Guerra Editora, 2018, p.12.

3 CARDOSO, S. O olhar dos viajantes (do etnólogo). In: NOVAES, A. (Org.) O olhar, São Paulo: Cia das Letras, 1988, p.360.

4 BAKHTIN, M. Questões de Literatura e Estética (A Teoria do Romance). São Paulo, Ed. Unesp, 1998, p. 211.
} 
tempo aberto ao poder do acaso, às coincidências e às novas oportunidades ${ }^{5}$. E qual seria o sentido da aventura para Lina? Seria a aventura do projeto moderno. Lina Bo Bardi vai assimilar essa outra realidade e se aventurar nesse mundo de aspectos extraordinários, estranhos e raros. Em 1946, o encontro com Chateaubriand, dono dos Diários Associados, cria a oportunidade que leva o casal Bardi a ocupar uma posição privilegiada. Um acaso que possibilitou que P.M. Bardi viesse a ser o diretor do Museu de Arte de São Paulo.

Para Lina vieram as oportunidades para projetar que haviam Ihe faltado na Itália. Pôde pensar em maneiras de expor, de visualizar a obra de arte. Em metal e vidro, projetou vitrines e painéis expositivos. Datam de 1947, suas propostas para museus de arte, tanto na Rua do Ouvidor, R], quanto na Rua 7 de Abril, SP, onde seu olhar moderno para o design já se evidenciava na cadeira com assento móvel do auditório. Experiências com o desenho de mobiliário foram feitas no Estúdio Palma (1948), em parceria com G. Palanti, e chegaram a sua melhor expressão com a cadeira Bardi's Bowl (1951). "Lina pertence ao mundo vital do segundo pós-guerra e ao mundo intelectual das primeiras vanguardas artísticas e políticas. Ela faz parte de uma geração que considera o surrealismo como o último movimento artístico-ético"6. A alusão ao surreal se faz presente no projeto para a cidade de São Vicente, SP, de um Museu à Beira do Oceano (1951). De outra parte, como editora da Revista Habitat (figura 01), Lina firmou posições no campo da crítica da cultura, estabelecendo vínculos com posições de vanguarda na arte e na arquitetura modernas de seu tempo.

Peixoto assinala que "aquele que não é do lugar, que acabou de chegar, é capaz de ver aquilo que os que lá estão não podem mais perceber (...) Ele é capaz de olhar as coisas como se fosse pela primeira vez e de viver histórias originais"7. Lina Bo Bardi se naturalizou brasileira. Em 1951, a Casa de Vidro (figura 02) traz consigo um modo particular de ver a arquitetura integrada à paisagem. $\mathrm{O}$ arquétipo da "casa urbana, familiar", caracteriza o lugar onde viria a tomar corpo um segundo cronotopo, em que Lina buscou a "integridade da existência idílica e sua ligação orgânica com a natureza"8 em associação ao habitar moderno.

Ao escrever Contribuição Propedêutica ao Ensino da Teoria da Arquitetura, em 1957, Lina Bo Bardi inclui uma ampla iconografia reveladora de seu olhar, resultante da associação entre campos diversos da cultura. Questões de interpretação, de história e de crítica fundamentam uma concepção

\footnotetext{
5 O cronotopo seria resultante de uma poética histórica em que se evidencia também a imagem do "indivíduo histórico real” (BAKHTIN, op. cit.,1998).

6 OLIVEIRA, O. Lina Bo Bardi: Sutis Substâncias da Arquitetura. São Paulo: Romano Guerra, 2006, p.15.

7 PEIXOTO, N. B. O Olhar Estrangeiro. In: NOVAES, op. cit., p.363.

8 BAKHTIN, op. cit., p.340.
} 


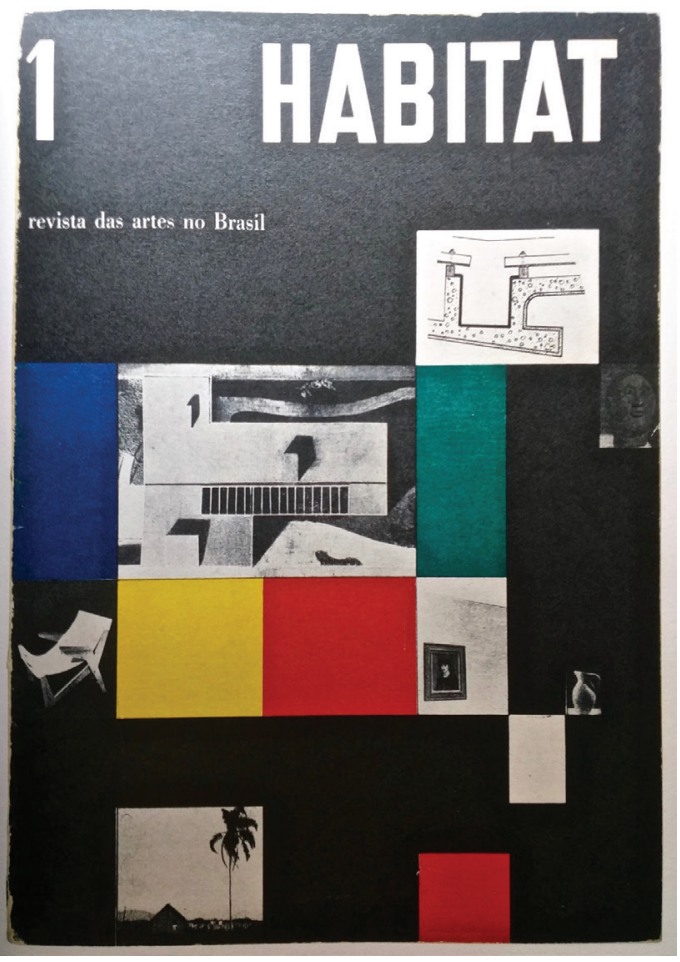

[Figura 01] Lina Bo Bardi e Pietro Maria Bardi (editores). Revista Habitat No 1 (capa). 1951. In: FERRAZ, 2018

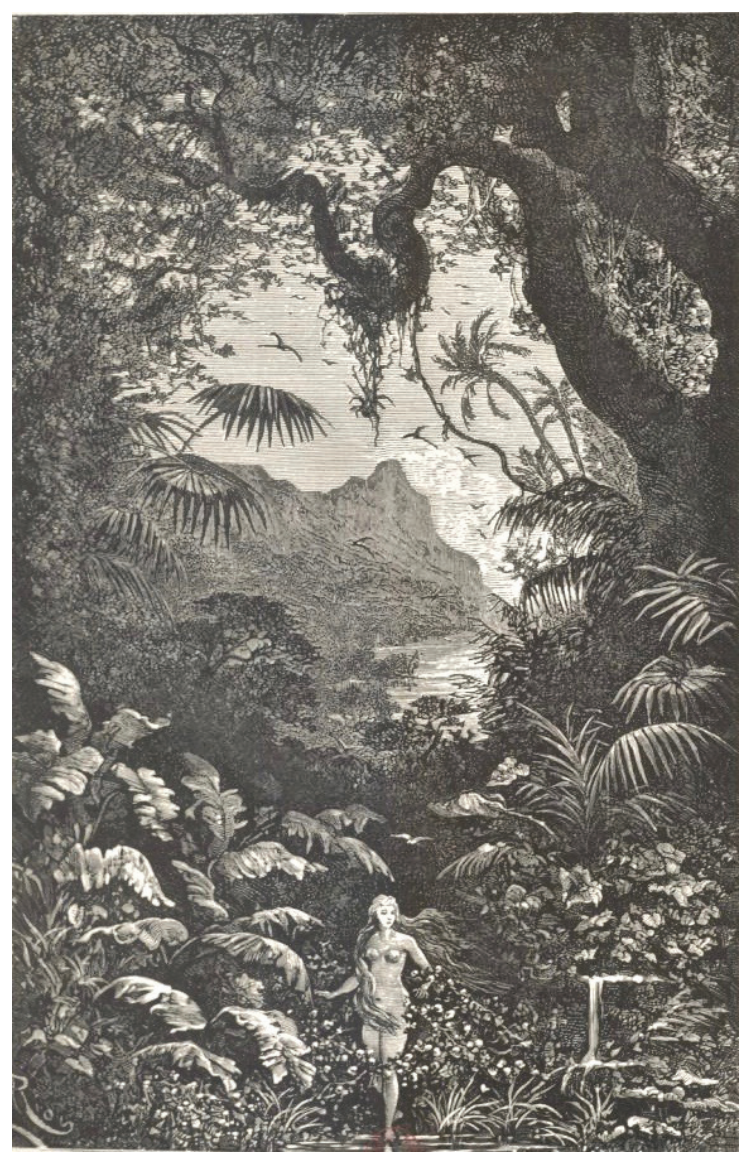

[Figura 04] Édouard Riou (ilustração), F. Méaulle (gravura). L'Éden. 1878.

In: MULLER, Eugène. La forêt : son histoire, sa légende, sa vie, son rôle, ses habitants. Paris: P. Ducrocq, 1878. Disponível em: gallica.bnf.fr / BnF. Acesso em: 22/11/19.

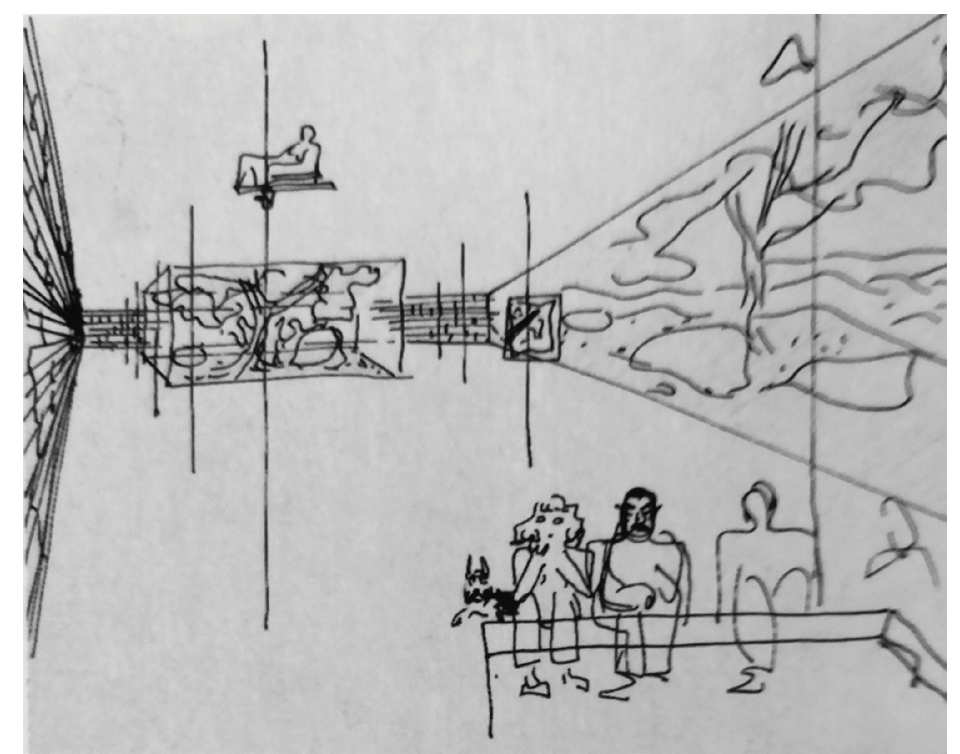

[Figura 03] Filarete (Antonio Averulino), Arquitetura fantástica. (1400-1469).

In: BARDI, 2002.

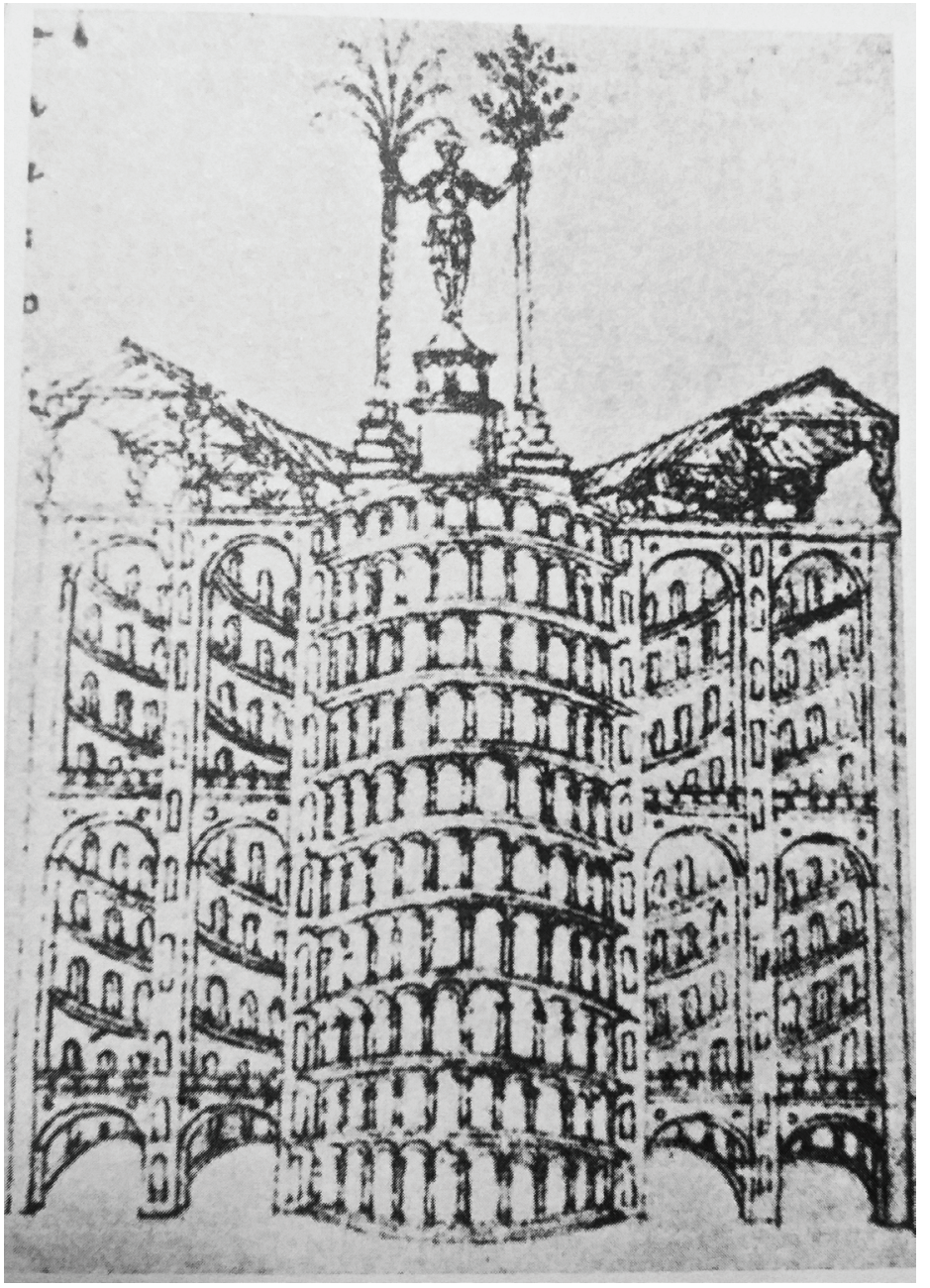

[Figura 02] Lina Bo Bardi. Casa de Vidro, primeiro croquí. 1951. In: FERRAZ, 2018. 
da arquitetura "à dispositio humana". J. M. Montaner aponta que "todo o texto é marcado pelo conhecimento da história e por uma preocupação humanista. Neste sentido, é um livro que se situa na tradição dos tratados italianos do Renascimento"9. Lado a lado à referências da arquitetura e da arte modernas, ilustram o texto imagens renascentistas como o Cataclisma, de Da Vinci, e a Arquitetura Fantástica de Filarete (figura 03), ambas representações alegóricas da capacidade de criação e realização humanas. Lina observa que é a presença humana que dá sentido à arquitetura. A figura humana é a protagonista, emprestando sentido a seus espaços e suas relações. Visões de uma arquitetura concebida em conformidade com a natureza emergem a partir das imagens idílicas (figura 04) de um romantismo que prenuncia o moderno ${ }^{10}$. A Casa Cirell (São Paulo, 1958), é um exemplo singular do modo com que Lina vai elaborar novas sínteses estéticas a partir da ideia de integração entre natureza e artifício.

Olho sobre a Bahia

\begin{abstract}
Esses estrangeiros viram em nossos trópicos, como que numa inversão do quadro europeu, o mundo novo onde vivia uma gente especial e onde tudo era possível (...) O Brasil é visto por eles, em última análise, como a possibilidade palpável de constituição de um emissor cultural ao mesmo tempo novo e profundo."1
\end{abstract}

Agier escreve que é a partir do distanciamento de si, para além dos círculos privados e naturalizados, que se cria uma relação com "aqueles que são ainda desconhecidos e se tornarão suficientemente próximos, um dia, para que um conhecimento nasça desse encontro"12. Lina Bo Bardi viveu na Bahia entre os anos de 1958 e 1964. Foi convidada pelo governador Juracy Magalhães a dirigir o Museu de Arte Moderna da Bahia, e convidada pelo reitor Edgar Santos a lecionar Teoria e Filosofia da Arquitetura, na Universidade Federal da Bahia. Um período que se caracteriza por uma conjunção de cronotopos. A "aventura" se renova de oportunidades e estranhamentos do olhar. Por outro lado, o elogio e o enamoramento ao Nordeste são evidenciados. O povo compõe parte deste cenário idílico, caracterizando um cronotopo de "uma certa sublimação filosófica (rousseauniana): no primeiro plano se destaca a profunda humanidade do homem idílico em si mesmo e as relações

\footnotetext{
9 MONTANER, J. M. Arquitetura e Crítica na América Latina. São Paulo: Romano Guerra, 2014, p.151.

10 Cf. BARDI, L. B. Contribuição Propedêutica ao Ensino da Teoria da Arquitetura. São Paulo, Instituto Lina Bo e P.M. Bardi, 2002.

11 RISÉRIO, A. Avant-garde na Bahia. São Paulo, Instituto Lina Bo e P.M. Bardi, 1995, p.89.

12 AGIER, M. Encontros etnográficos: interação, contexto, comparação. São Paulo: Ed. Unesp, Alagoas: Edufal, 2015, p.19.
} 
humanitárias entre as pessoas"13. Lina se apaixonou pela cultura popular do Nordeste.

"Cumpria mapear a paisagem humana e cultural que ia surgindo e se desdobrando, em ondulações barrocas, à sua frente" ${ }^{1_{14}}$. Seu olhar descortinou o recôncavo e o sertão baianos. Conforme sua visão, "a Bahia poderia, sim, assumir uma função de centro cultural, embora fosse, economicamente, uma região periférica"15. Na universidade, não era a única estrangeira. Havia outros olhares da vanguarda lecionando em Salvador no mesmo período. Eram europeus imigrantes, como o maestro austríaco Koellreutter, a coreógrafa polonesa Yanka Rudzka, e o filósofo português Agostinho Silva, nomes que deixaram um legado para a renovação cultural da Bahia daqueles anos ${ }^{16}$.

Em 1958, o jornal Diário de Notícias publicou em Salvador as Crônicas de arte, de história, de costume, de cultura da vida. As Crônicas, editadas por Lina Bo Bardi, traziam artigos de sua autoria, como Cultura e não cultura e A escola e a vida. Seu olhar se revelava na seleção de imagens que ilustravam a página, incluindo desenhos de sua autoria como Paisagem mecanizada (figura 07). Na construção desse olhar sobre a cultura baiana, colaboraram com as Crônicas nomes como o de Koellreutter, Pierre Verger, Mário Cravo Junior, Martins Gonçalves, Gianni Ratto, Silvio Robatto e Ennes S. Mello, personagens do contexto cultural de Salvador, cada qual contribuindo com sua visão singular. Desde artigos sobre a "música concreta" até a fotografia etnográfica, passando pela arquitetura, a escultura e o teatro. Na seção Ôlho Sôbre A Bahia ${ }^{17}$, nota-se a singularidade da visão editorial de Lina e a sua evidência em imagem (figura 06).

As Crônicas revelavam um projeto que se articulava a partir do campo da cultura. A crítica sobre a obra de Lina Bo Bardi sublinha que sua atuação cultural se fundamenta também na filosofia de Gramsci. As ideias do pensador italiano eram ainda pouco conhecidas. Rubino escreve que, segundo depoimento de Carlos Nelson Coutinho" ${ }^{18}$, Lina "foi a primeira pessoa a falar de Gramsci em nosso país"19. Atuava como uma "intelectual orgânica", no sentido gramsciano do termo, em permanente ação cultural transformadora. Nesse sentido, via na filosofia e na arte um meio para a prática política. Via no museu um sentido educativo, um lugar estratégico para a construção e organização culturais. Buscava estabelecer um sistema de relações que potencializasse o campo da cultura popular. Segundo Oliveira, a arquiteta era "multifacetada", "sua obra extrapola os limites da arquitetu-

\footnotetext{
13 BAKHTIN, op. cit., p.340.

14 RISÉRIO, op. cit., p.135.

15 Ibid, p.135.

16 Cf. RISÉRIO, op. cit.,1995

17 Foi mantida a grafia original do título.

18 Cf. GRAMSCI, A. Concepção dialética da História. Trad. C. N. Coutinho. Rio de Janeiro: Civilização Brasileira, 1995 [1a ed. 1966]

19 RUBINO, S., GRINOVER, M. (org.). Lina por escrito: textos escolhidos de Lina Bo Bardi. São Paulo, Cosac \& Naif, 2009, p.37.
} 


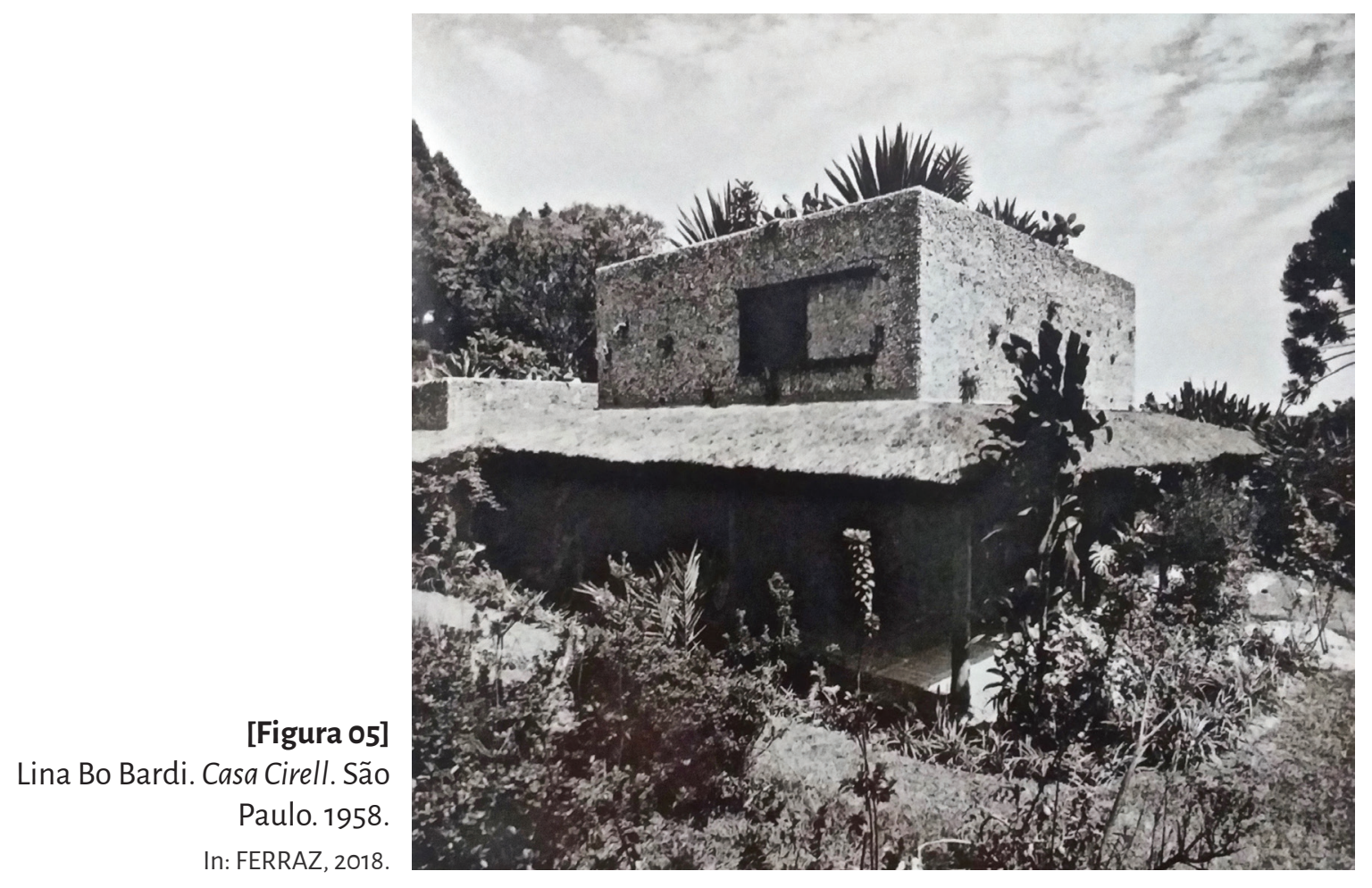

[Figura 06]

Lina Bo Bardi. Ôlho sôbre a

Bahia (detalhe). 1958.

In: FERRAZ, 2018.

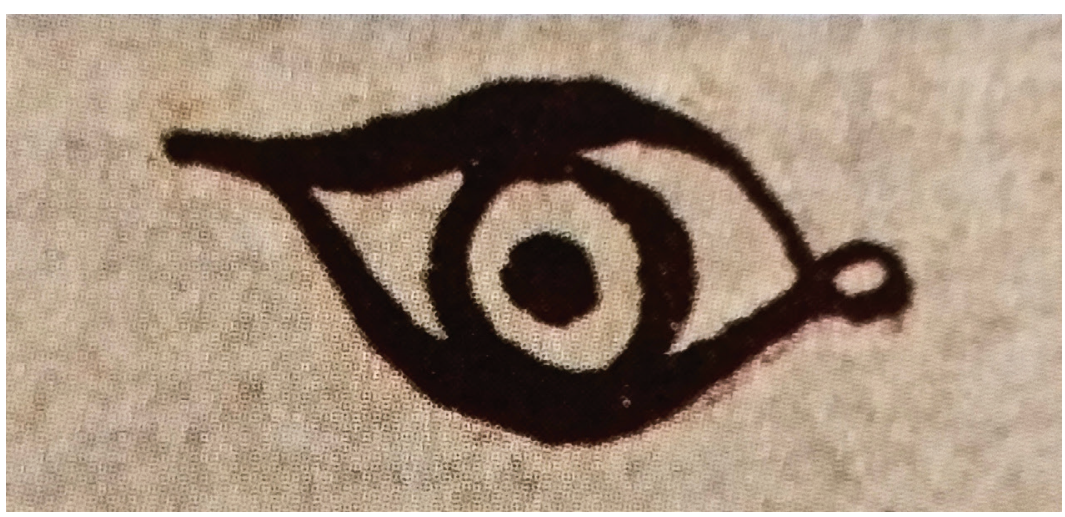

[Figura 07]

Lina Bo Bardi. Paisagem

Mecanizada. 1958.

In: RUBINO, GRINOVER, 2009

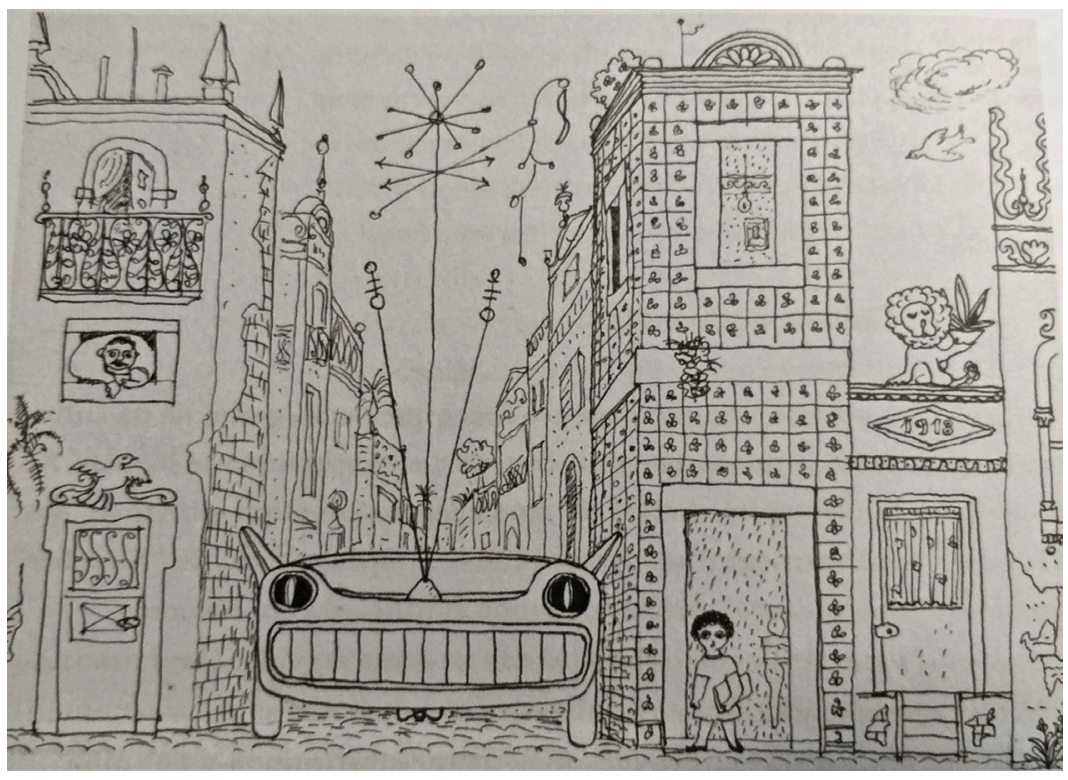


ra para atingir outros domínios disciplinares tal como o das artes, da filosofia, da antropologia, da literatura, ou da psicanálise"20.

Lintellettuale gramsciano è un artista legato a un popolo, che deve contemporaneamente esaltarne la voce e creare gli spazi nei quali quel popolo possa respirare a pieni polmone, divertirsi e ricrearsi, d'accordo con idue significati della parola ricreazione. solo attraverso questo dialogo con l'elemento popolare e dentro di esso, l'intellettuale moderno svolge, secondo l'insegnamento politico di Cramsci, la funzione secolare e moderna di chiarimento filosofico, unione solidale ed emancipazione dall'oppressione, da dovunque essa venga. questo faceva Lina Bo Bardi. ${ }^{21}$

"Lina é o olhar antropológico da avant-garde captando e iluminando atos e produtos da mestiçaria"22. Afinal, o que trouxe de novo o olhar estrangeiro dessa arquiteta que vivia o Nordeste entre a aventura e o idílio, mas sobretudo produzindo e elaborando projetos? Do período em que viveu em Salvador, seus projetos e obras realizados compõem um mosaico de seu modo de olhar: a singular Casa Do Chame-Chame (Salvador, 1958); a exposição Bahia No Ibirapuera (figura 08), em parceria com M. Gonçalves, e que participa da V Bienal de São Paulo (1959); a cenografia da Ópera De Três Tostões (de Brecht e Weill) e os figurinos de Calígula (de Camus), ambas peças encenadas em Salvador (1960 e 1961) e dirigidas por M. Gonçalves; e ainda a Exposição Nordeste (figura 10), organizada por Lina Bo Bardi no Museu de Arte Moderna da Bahia (1963).

Na obra do Solar do Unhão (1959-1963), o olhar de Lina se revelou, sobretudo, estrangeiro. Em Critério proposto para a restauração do 'Solar do Unhão', ela se alinha ao método da "restauração crítica" cujo critério parte da identificação de uma poética pertinente ao conjunto, "dentro da interpretação moderna da continuidade histórica, procurando não embalsamar o monumento, mas integrá-lo ao máximo na vida moderna"23. Esta postura confrontava o olhar dos técnicos do SPHAN ${ }^{24}$ regional, preocupados em "abrasileirar" o conjunto, e alinhados ao "restauro científico", filológico, cujos procedimentos Lina utilizava "somente como fato de método e não como fim"25. No Unhão, Lina valoriza a ambiência e a poética do conjunto, destacando a volumetria dos edifícios e liberando os espaços para circulação e visualização. No partido, a Capela de Nossa Senhora da Conceição opera como elemento definidor do espaços de circulação e articulação. A intervenção remete ao diradamento

\footnotetext{
20 OLIVEIRA, op. cit., p.15.

21 SUBIRATS, E. Lina Bo: "Un'epoca Nuova Ė Già Cominciata”. In: GALLO, A. (org.). Lina Bo Bardi Architetto. Veneza, Marsilio, 2004, P.31.

22 RISÉRIO, op. cit., p.111

23 BARDI, 1962 apud CERÁVOLO, A. L. Interpretações do patrimônio: arquitetura e urbanismo moderno na constituição de uma cultura de intervenção no Brasil-1930-1960. São Carlos: EdUFSCar, 2013, p.197.

24 Antigo Serviço do Patrimônio Histórico e Artístico Nacional, atual IPHAN.

25 Ibid, p.197.
} 


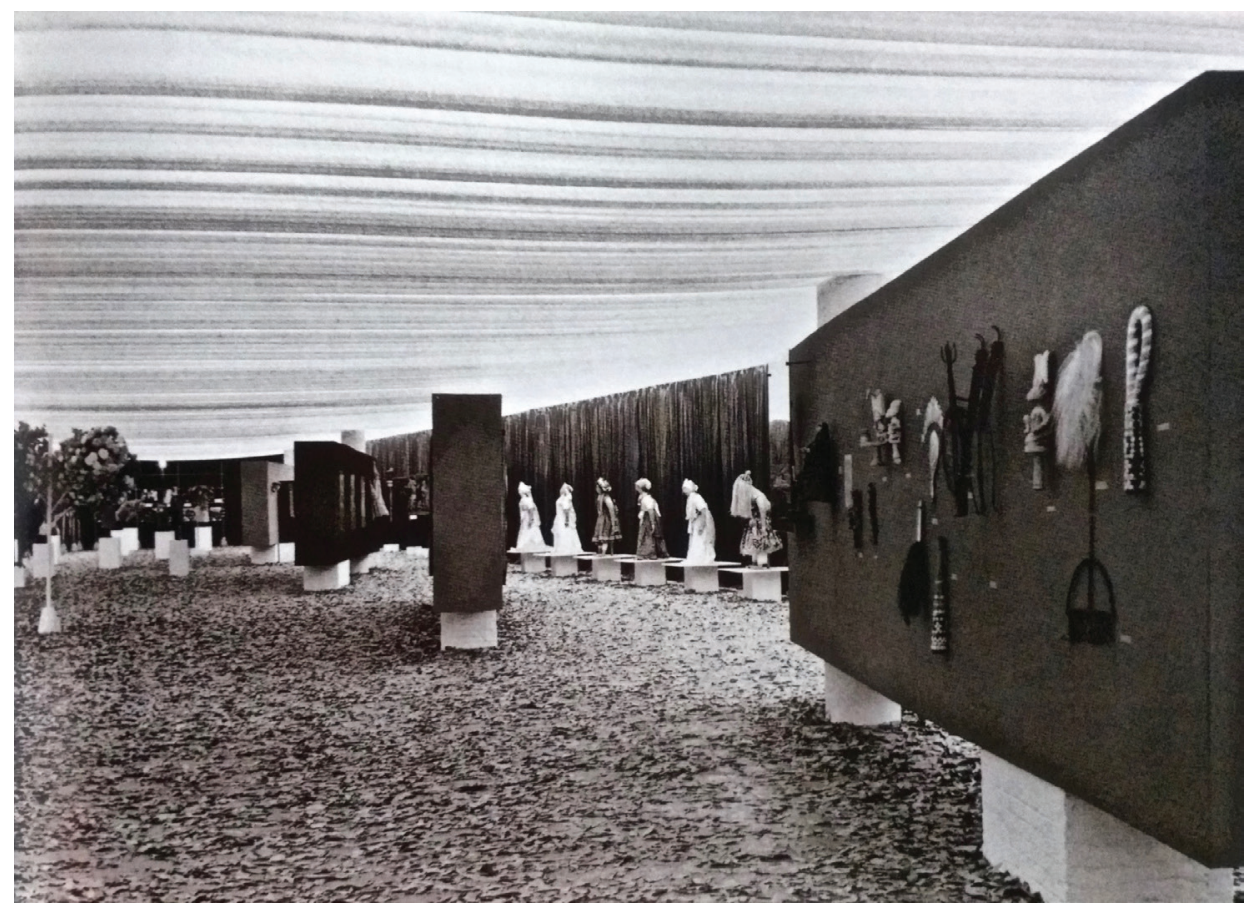

[Figura 08] Lina Bo Bardi e Martim Conçalves. Exposição Bahia no Ibirapuera, V Bienal de São Paulo. 1959.

In: FERRAZ, 2018.

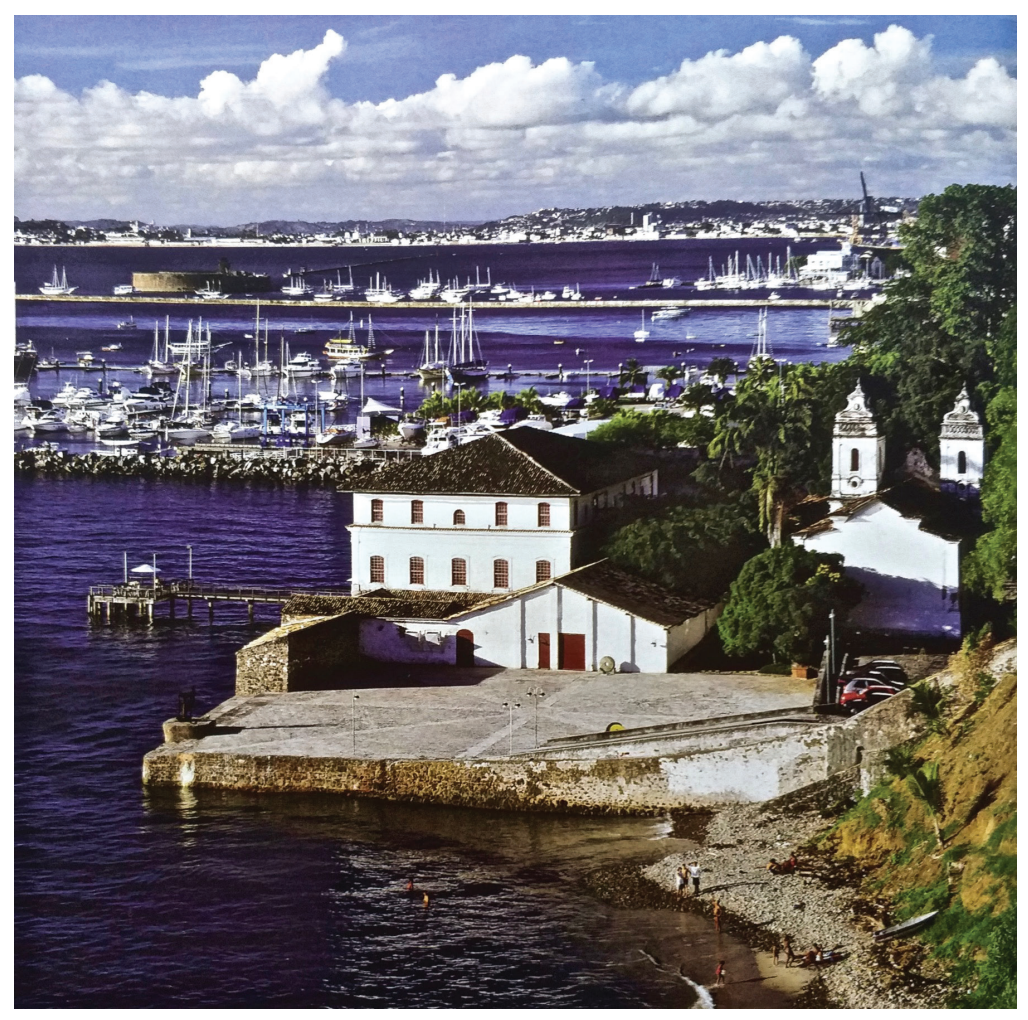

[Figura 09] Lina Bo Bardi. Solar do Unhão. 1959-1963.

Fotografia: Nelson Kon. In: OLIVEIRA, O. Lina Bo Bardi: obra construída Built work. São Paulo: Gustavo Gili, 2014.

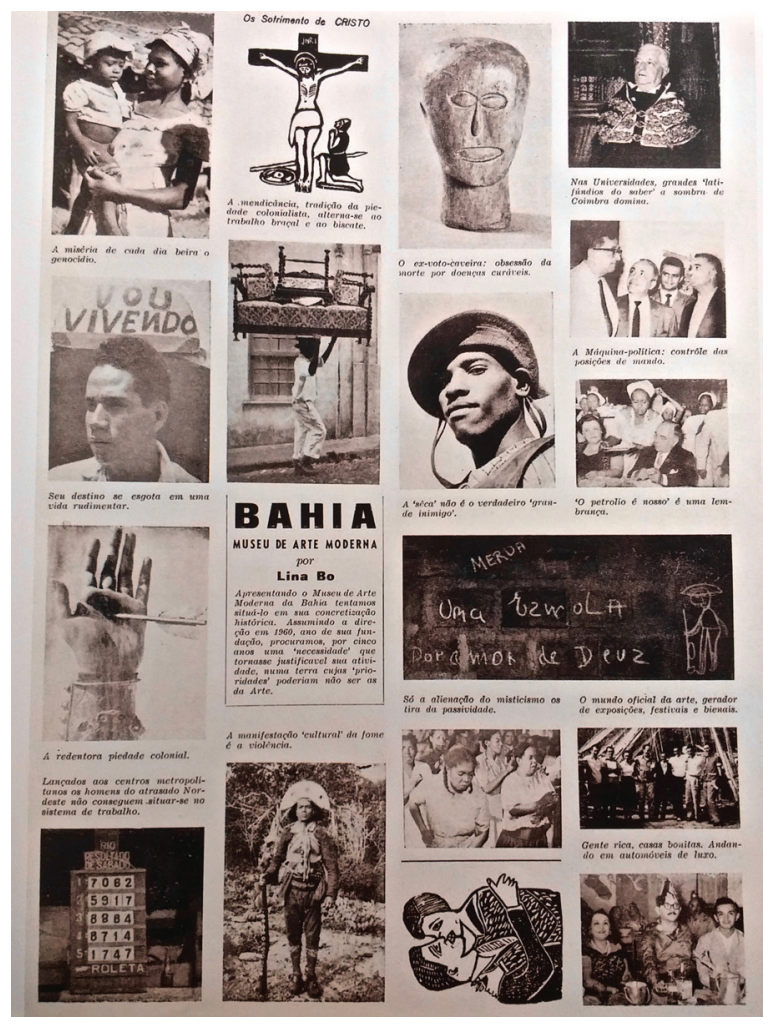

[Figura 10] Lina Bo Bardi. Exposição Nordeste, Solar do Unhão, Salvador. 1963.

In:. FERRAZ, 2018 
edilizio ${ }^{26}$ de Giovannoni. A integridade da nave da igreja é valorizada pelo "desbastamento" de acréscimos no fundo e nas laterais. É eliminado um galpão na plataforma do cais, com a implantação de uma praça à beira mar (figura 09). A inserção de aberturas na fachada da frente marítima potencializa as vistas. Por meio de "una nitidezza orientale degli spazi"27, Lina Bo Bardi procura humanizar e ampliar a fruição do lugar, reforçando a percepção de um caráter local relacionado à paisagem, à identidade e à memória.

Considerações Finais

E o europeu se redimensiona radicalmente nesse mergulho: o olhar sobre o outro retorna sobre si mesmo. ${ }^{28}$

Em 1964, com a tomada do poder pelos militares, Lina deixa a direção do Museu de Arte Moderna da Bahia e a cidade de Salvador. Estes eventos levam a um terceiro cronotopo, que se caracteriza pela ideia de "destruição do idílio". Lina se encontra com o Brasil das contradições políticas. Observa e compreende o contexto como naturalizada brasileira. O cronotopo leva a uma determinada compreensão acerca do mundo idílico que chega ao seu fim, e conduz a um julgamento acerca deste mesmo mundo e da "força destruídora" que age sobre ele. O mundo capitalista em devir vai ganhar contornos desagregadores, degenerativos de princípios e valores constituídos na sociedade $^{29}$. O olhar estrangeiro de Lina Bo Bardi havia se confrontado com uma visão conservadora no contexto da sociedade baiana. "Lina era a estrangeira, a intrusa (e mulher ainda por cima)"30. Com a mudança política, Lina não vê outra alternativa que não retornar a São Paulo.

No ano de 1964, ao deixar a cidade de Salvador, Lina era outra. Seu olhar havia mudado e seus horizontes haviam se ampliado. Não eram as imagens de um progresso moderno sonhado desde Milão e avistado nas américas. Antes eram as figuras e tradições populares do Nordeste, que agora povoavam o imaginário da arquiteta e aguçavam um novo olhar mestiço. Antes eram a estética do barroco e a beleza de uma história viva e presente. A partir das obras do Solar do Unhão e do Masp, Lina lança a semente de outros olhares possíveis. A valorização das memórias e das artes populares,

\footnotetext{
"Desbastamento de edifícios", em tradução livre.

SUBIRATS, op. cit., p.42.

RISÉRIO, op. cit., p.89.

29 Cf. BAKHTIN, op. cit.,1998.

30 RISÉRIO, op. cit., p. 25.
} 
os museus que educam, que ensinam a ver e ressignificar o mundo. Da leitura de Agier ${ }^{31}$, anota-se que o olhar estrangeiro surge, sobretudo, depois de uma partida rumo ao novo e ao desconhecido. Dessa atitude fundadora deriva a necessidade de aprender a se orientar em um espaço ao qual não se pertence, e no qual é preciso antes se perder para que a descoberta das chaves de leitura do lugar se torne possível.

eferências bibliográficas

AGIER, M. Encontros etnográficos: interação, contexto, comparação. São Paulo: Ed. Unesp, Alagoas: Edufal, 2015.

BAKHTIN, M. Questões de Literatura e Estética (A Teoria do Romance). São Paulo: Ed. Unesp, 1998.

BARDI, L B. Contribuição Propedêutica ao Ensino da Teoria da Arquitetura. São Paulo, Instituto Lina Bo e P.M. Bardi, 2002.

CARDOSO, S. O ol har dos viajantes (do etnólogo). In: NOVAES, A. (Org.) O olhar, São Paulo: Cia das Letras, 1988.

CERÁVOLO, A. L. Interpretações do patrimônio: arquitetura e urbanismo moderno na constituição de uma cultura de intervenção no Brasil -1930-1960. São Carlos: EdUFSCar, 2013.

FERRAZ, M. C. (Org). Lina Bo Bardi. São Paulo, Instituto Bardi: Casa de Vidro: Romano Guerra, 2018.

GIOVANNONI, G. Gustavo Giovannoni. Textos Escolhidos. Org. KUHL, B. M. C., São Paulo: Ateliê Editorial, 2013.

GRINOVER, M. M. Lina Bo Bardi e Glauber Rocha: diálogos para uma filosofia da "práxis". In: Seminário 50 Anos de Lina Bo Bardi na Encruzilhada da Bahia e do Nordeste. Salvador, PPGAU-UFBA, 2009. Disponível em: http://www. docomomobahia.org/linabo/ Acesso em: 22/10/2018.

LAURENTIZ, L. C. "Olhos Sobre A Bahia" Pelos Olhos De Lina, 1958. In: Seminário 50 Anos de Lina Bo Bardi na Encruzilhada da Bahia e do Nordeste. Salvador, PPGAU-UFBA, 2009. Disponível em: http://www.docomomobahia.org/ linabo/. Acesso em: 22/10/2018.

MONTANER, J. M. Arquitetura e Crítica na América Latina. São Paulo: Romano Guerra, 2014.

OLIVEIRA, O. Lina Bo Bardi: Sutis Substâncias da Arquitetura. São Paulo: Romano Guerra, 2006.

PEIXOTO, N. B. O Olhar Estrangeiro. In: NOVAES, A. (Org.) O olhar, São Paulo: Cia das Letras, 1988.

RISÉRIO, A. Avant-garde na Bahia. Sao Paulo, Instituto Lina Bo e P.M. Bardi, 1995.

RUBINO, S., GRINOVER, M. (Org.). Lina por escrito: textos escolhidos de Lina Bo Bardi. São Paulo, Cosac \& Naif, 2009. SUBIRATS, E. Lina Bo: "Un'epoca Nuova Ė Già Cominciata". In: GALLO, A.(org.). Lina Bo Bardi Architetto. Veneza, Marsilio, 2004.

31 Cf. AGIER, op. cit., 2015. 